\title{
Halogen-Bonded Co-Crystals of Aromatic N-oxides: Polydentate Acceptors for Halogen and Hydrogen Bonds
}

\author{
Rakesh Puttreddy * (D), Filip Topić (D), Arto Valkonen (D) and Kari Rissanen * (D) \\ Department of Chemistry, University of Jyvaskyla, P.O. Box 35, FI-40014 Jyvaskyla, Finland; \\ filip.f.topic@jyu.fi (F.T.); arto.m.valkonen@jyu.fi (A.V.) \\ * Correspondence: rakesh.r.puttreddy@jyu.fi (R.P.); kari.t.rissanen@jyu.fi (K.R.); \\ Tel.: +35-850-562-3721 (R.P. \& K.R.)
}

Academic Editors: Peter Politzer and Jane S. Murray

Received: 7 June 2017; Accepted: 7 July 2017; Published: 11 July 2017

\begin{abstract}
Seventeen new halogen-bonded co-crystals characterized by single crystal X-ray analysis are presented from $8 \times 4$ combinations using methyl-substituted pyridine $N$-oxides and $1, \omega$-diiodoperfluoroalkanes. The $\mathrm{N}-\mathrm{O}$ group in six of 17 co-crystals is monodentate and 11 have $\mu-\mathrm{O}, \mathrm{O}$ bidentate halogen bond acceptor modes. Remarkably, the $\mathrm{N}-\mathrm{O}$ group in co-crystals of 3-methyl-, 4-methyl- and 3,4-dimethylpyridine $\mathrm{N}$-oxides with octafluoro-1,4-diiodobutane acted as a $\mu-O, O, O, O$ halogen and hydrogen bond acceptor, while acting as a $\mu-O, O, O$ acceptor in the co-crystal of 2,5-dimethylpyridine $\mathrm{N}$-oxide and tetrafluoro-1,2-diiodoethane. The $\mathrm{C}-\mathrm{H} \cdots \mathrm{O}-\mathrm{N}$ hydrogen bonds demonstrated the polydentate cooperativity of the $\mathrm{N}-\mathrm{O}$ group as a mixed halogen-hydrogen bond acceptor. The co-crystal of 2,4,6-trimethylpyridine $\mathrm{N}$-oxide and dodecafluoro-1,6-diiodohexane exhibited $\mathrm{C}-\mathrm{I} \cdots \mathrm{O}^{-}-\mathrm{N}^{+}$halogen bonds with $\mathrm{R}_{\mathrm{XB}}$ value 0.76 , the shortest of its kind compared to previously reported structures. The $\mathrm{R}_{\mathrm{XB}}$ values between 0.76 and 0.83 suggested that the $\mathrm{C}-\mathrm{I} \cdots \mathrm{O}^{-}-\mathrm{N}^{+}$halogen bonds are moderately strong compared to our previously studied $\mathrm{N}^{-}-\mathrm{I}^{+} \ldots$ $\mathrm{O}^{-}-\mathrm{N}^{+}$system, with $\mathrm{R}_{\mathrm{XB}}$ in the order 0.66 .
\end{abstract}

Keywords: halogen bond; hydrogen bond; aromatic $\mathrm{N}$-oxides; perfluoroalkyl; diiodoperfluoroalkanes; polydentate; $\mathrm{N}-\mathrm{O}$ group; cooperativity; $\mathrm{C}-\mathrm{H} \cdots \mathrm{O}$ interactions

\section{Introduction}

The halogen bond (XB), analogous to the hydrogen bond (HB), has been defined [1] as a net attractive interaction between an electrophilic region of a halogen atom bound to a molecular entity and a nucleophilic site in another moiety, e.g., a nitrogen, oxygen or sulphur atom [2]. This region of positive electrostatic potential, called the "sigma hole" [3,4], is characteristic for halogen atoms attached to an organic backbone, with its magnitude generally decreasing in the order $\mathrm{I}>\mathrm{Br}>$ $\mathrm{Cl}>\mathrm{F}$. Despite similar geometrical features between $\mathrm{HB}$ and $\mathrm{XB}$, the halogen bond is still not as well-explored compared to the ubiquitous HB [5-9]. Halogen bonds are frequently studied using nitrogen compounds, which typically display monovalent $\mathrm{N} \cdots \mathrm{X}(\mathrm{X}=\mathrm{I}, \mathrm{Br})$ interactions and are well understood as crystal engineering tools for self-assembly processes. Their precedence from discrete structures to increased dimensionality through the controlled reactivity of substrates is well-reported [10-13]. In a solid-state $X B$ complex, $R-X \cdots B-Z$, where $X$ is the donor and $B$ is the acceptor atom, the ratio of the short distance between $X$ and $B$ atoms $\left(d_{X-B}\right)$ to sum of the Van der Waals radii of $\mathrm{X}$ and $\mathrm{B}$ atoms $\left(d_{v d W}\right)$ is defined as the normalized strength parameter, $R_{\mathrm{XB}}=d_{X-B} / d_{v d W}[1]$. Knowledge of $R_{X B}$ values provides an opportunity to roughly estimate the strengths of $X B$ complexes. For example, the $\mathrm{X} \cdots \mathrm{N}$ distances in bis(pyridine)iodonium(I) tetrafluoroborate constitute an $R_{\mathrm{XB}}$ value 
of 0.65 , and such compounds are classified as halogen bonds of covalent nature [14]. Carefully designed nitrogen compounds are successfully utilized as molecular building blocks engaging in $(\mathrm{N}-\mathrm{X}-\mathrm{N})^{+} \mathrm{X}^{-}$ $\mathrm{XBs}$ to construct supramolecular structures resembling metal coordination frameworks [15]. However, weaker $\mathrm{C}-\mathrm{I} \cdots \mathrm{N}$ XBs with typical $\mathrm{R}_{\mathrm{XB}}$ values ranging from 0.75 to 0.90 are still of considerable importance for applications in materials chemistry, e.g., for triggering liquid crystallinity and gelation behaviour [16-18].

Aromatic $\mathrm{N}$-oxides have been long known in heterocyclic chemistry for functionalized pyridines syntheses [19-25]. Besides being valuable synthetic intermediates, the dipolar neutral $\mathrm{N}^{+}-\mathrm{O}^{-}$group exhibits a push-pull property towards aromatic rings, enabling it to undergo both electrophilic and nucleophilic substitution reactions, categorizing these compounds as promising building blocks in supramolecular chemistry [26,27]. Electron-donating and electron-withdrawing substituents on aromatic ring invoke different hybridization states on oxygen in the $\mathrm{N}-\mathrm{O}$ group [28,29], allowing for tuning of its complexation behaviour towards metals [30,31].

Strategic exploitation of $\mathrm{XB}$ acceptor properties for heteroatoms, such as oxygen, remains very much unknown in the literature. A Cambridge Structural Database (CSD) search for pyridine $N$-oxides functioning as $\mathrm{XB}$ acceptors revealed only a handful of structures (see supporting information for more details), while their systematic investigations remain especially scarce [32-34]. Previously, monodentate strong $\mathrm{N}^{-}-\mathrm{I}^{+} \ldots \mathrm{O}^{-}-\mathrm{N}^{+}$XBs ( $\mathrm{R}_{X B}$ as low as 0.66 ) of coordinative nature between pyridine $\mathrm{N}$-oxides and N-haloimides were studied both in solution and in the solid-state [35]. Here, we aimed to investigate $\mathrm{C}-\mathrm{I} \cdots \mathrm{O}^{-}-\mathrm{N}^{+}$XBs using $1, \omega$-diiodoperfluoroalkanes (DI2-DI8) and methyl-substituted aromatic $N$-oxides (1-8), as shown in Figure 1. Haloperfluoroalkanes are robust $\mathrm{XB}$ donors, and their ability to steer the supramolecular assembly by XBs and F $\cdots F$ interactions is well described [36]. However, the volatile nature of these compounds often results in oily or waxy substances, which are difficult to characterize using single crystal X-ray diffraction [18,37]. Despite their reluctance to crystallize, our attempts from $8 \times 4$ (acceptor $\times$ donor) combinations resulted in 17 crystal structures, providing an impressive crystallization success rate to analyze and understand the interactions at play in their solid-state structures.

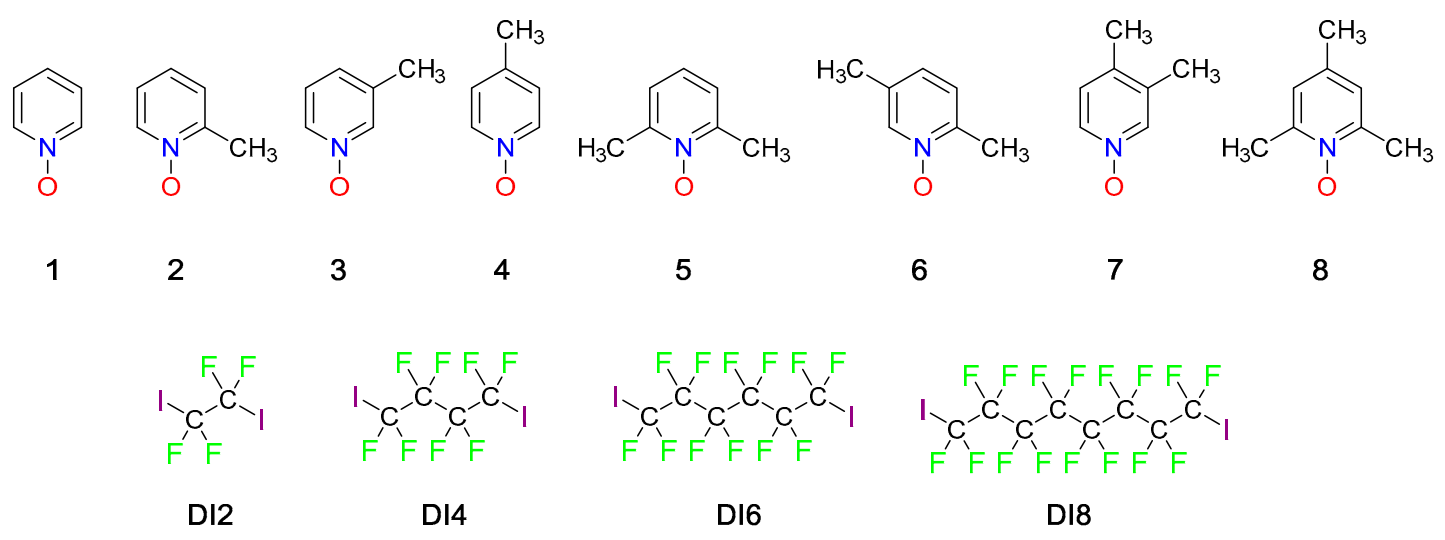

Figure 1. The chemical structures of acceptors (top) and donors (below) in the current study: pyridine $\mathrm{N}$-oxide (1), 2-methylpyridine $\mathrm{N}$-oxide (2), 3-methylpyridine $\mathrm{N}$-oxide (3), 4-methylpyridine $\mathrm{N}$-oxide (4), 2,6-dimethylpyridine $N$-oxide (5), 2,5-dimethylpyridine $N$-oxide (6), 3,4-dimethylpyridine $N$-oxide (7), 2,4,6-trimethylpyridine $N$-oxide (8), tetrafluoro-1,2-diiodoethane (DI2), octafluoro-1,4-diiodobutane (DI4), dodecafluoro-1,6-diiodohexane (DI6) and hexadecafluoro-1,8-diiodooctane (DI8).

\section{Results and Discussion}

The methods used to obtain the single crystals suitable for X-ray analysis are shown in Table S1.

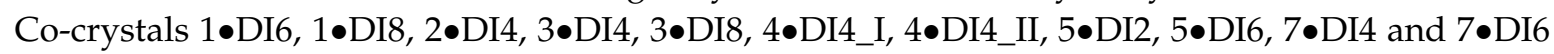
all form infinite 1-D polymers, and $4 \bullet$ DI4_I and $4 \bullet$ DI4_II are polymorphs. The co-crystals were grouped and discussed based on structural similarities observed in the crystal packing. Halogen 
bonds between $\mathrm{N}-\mathrm{O}$ and $\mathrm{C}-\mathrm{I}$ groups were explored as the driving force propagating 1-D polymers with alternate acceptors and donors. The XB interaction bond parameters are shown in Table 1 . In $1 \bullet$ DI6, $1 \bullet$ DI 8 and $3 \bullet$ DI 8 , the aromatic rings and donors were essentially coplanar, in contrast to the orthogonal alignment typically observed in coordination compounds [30,31]. The $\mathrm{N}-\mathrm{O}$ groups were $\mu-O, O$ bidentate, bridging the donors to form remarkably similar 1-D polymeric chains, as shown in Figure 2. Further analysis of the crystal packing revealed the donor-acceptor parallel arrangement to be a result of F $\cdots$ F aggregation [38-42] between perfluorinated donor chains, which, though weaker than $\mathrm{C}-\mathrm{I} \cdots \mathrm{O}^{-}-\mathrm{N}^{+} \mathrm{XBs}$, play a crucial role to yield a robust 3-D crystal structure.

Table 1. Bond parameters for co-crystals $1 \bullet$ DI6-8•DI6.

\begin{tabular}{|c|c|c|c|c|c|}
\hline \multirow{2}{*}{ S.No } & \multirow{2}{*}{ Code } & \multicolumn{2}{|c|}{ Monodentate } & \multicolumn{2}{|c|}{$\mu-O, O$} \\
\hline & & $c a . d(\mathrm{I} \cdots \mathrm{O}-\mathrm{N}) / \AA^{*}$ & $\angle(\mathrm{C}-\mathrm{I} \cdots \mathrm{O}) /^{\circ}$ & ca. $d(\mathrm{I} \cdots \mathrm{O}-\mathrm{N}) / \AA$ * & $\angle(\mathrm{C}-\mathrm{I} \cdots \mathrm{O}) /^{\circ}$ \\
\hline 1 & $1 \bullet$ DI6 & $2.834[0.81]$ & 177.1 & $* *$ & $* *$ \\
\hline 2 & $1 \bullet$ DI8 & $2.833[0.81]$ & 177.7 & $* *$ & $* *$ \\
\hline 3 & $2 \bullet \mathrm{DI} 4$ & $2.747[0.79]$ & 174.2 & $2.861[0.82]$ & 178.9 \\
\hline 4 & $3 \bullet$ DI4 & $2.840[0.81]$ & 172.1 & $2.875[0.82]$ & 168.8 \\
\hline 5 & $3 \bullet$ DI8 & $2.809[0.80]$ & 174.8 & $2.817[0.81]$ & 174.7 \\
\hline 6 & $4 \bullet$ DI4_I & $2.808[0.80]]^{* * *}$ & $172.3^{* * *}$ & $2.813[0.80]^{* * *}$ & $174.1 * * *$ \\
\hline 7 & $4 \bullet$ DI4_II & $2.766[0.79]$ & $177.5^{* * *}$ & $* *$ & $* *$ \\
\hline 8 & $5 \bullet \mathrm{DI} 2$ & $2.743[0.78]$ & $161.2 * * *$ & $* *$ & $* *$ \\
\hline 9 & $5 \bullet$ DI4 & $2.669[0.76]$ & $171.3^{* * *}$ & - & - \\
\hline \multirow[t]{2}{*}{10} & $5 \bullet$ DI6 & $2.733[0.78]$ & 175.5 & $2.774[0.80]$ & 169.0 \\
\hline & & $2.764[0.79]$ & 174.9 & $2.813[0.804]$ & 170.3 \\
\hline 11 & $6 \bullet \mathrm{DI} 2$ & $2.714[0.78]$ & 171.9 & - & - \\
\hline 12 & $7 \bullet \mathrm{DI} 2$ & $2.703[0.77]$ & 174.6 & - & - \\
\hline 13 & $7 \bullet \mathrm{DI} 4$ & $2.835[0.81]$ & $167.5^{* * *}$ & $2.906[0.83]$ & $170.0^{* * *}$ \\
\hline 14 & 7•DI6 & $2.825[0.81]$ & $167.9^{* * *}$ & $2.827[0.81]$ & $178.2^{* * *}$ \\
\hline 15 & $7 \bullet \mathrm{DI} 8$ & $2.715[0.78]$ & 176.5 & - & - \\
\hline \multirow[t]{2}{*}{16} & $8 \bullet \mathrm{DI} 2$ & $2.702[0.78]$ & 166.4 & - & - \\
\hline & & $2.775[0.79]$ & 170.8 & - & - \\
\hline \multirow[t]{2}{*}{17} & $8 \bullet$ DI6 & $2.649[0.76]$ & 174.3 & - & - \\
\hline & & $2.682[0.77]$ & 176.1 & - & - \\
\hline
\end{tabular}

* Respective $\mathrm{R}_{\mathrm{XB}}$ values are reported in parentheses [1]. ${ }^{* *}$ The other halogen bond is symmetrically equivalent. *** Major disorder component.

(a)

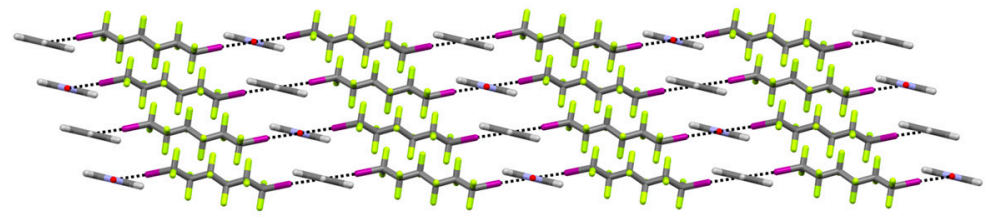

(b)
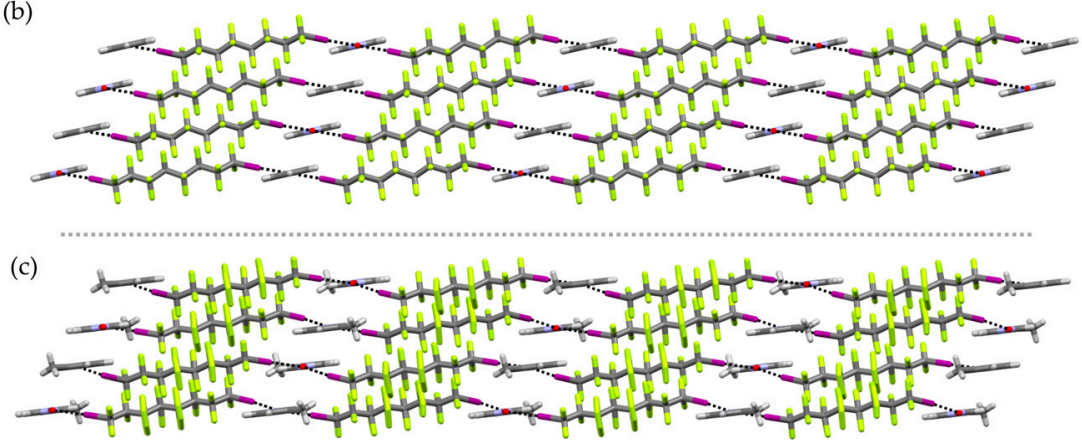

Figure 2. Section of the crystal packing showing structural similarity between 1-D parallel stacks in 1•DI6 (a), 1•DI8 (b) and 3•DI8 (c). 
The strength of the $\mathrm{C}-\mathrm{H} \cdots \mathrm{O}$ interaction is approximately one-third of conventional HBs [43-49] that operate between donors such as $-\mathrm{N}-\mathrm{H} /-\mathrm{O}-\mathrm{H}$ and weak bases, and these interactions significantly increase the lattice energy of the co-crystals [50]. The $\mathrm{C}-\mathrm{H} \cdots \mathrm{O}$ contacts are attractive, and are rather site acidity-dependent. For example, the $\mathrm{C} 2$-proton acidity in pyridine $\mathrm{N}$-oxides for ortho- $\mathrm{C}-\mathrm{H}$ functionalization in organic synthesis [19-25], and in crystal engineering for $\mathrm{C}-\mathrm{H} \cdots \mathrm{O}-\mathrm{N}$ interactions is well studied [51-54]. However, to the best of our knowledge, the combination of $\mathrm{C}-\mathrm{H} \cdots \mathrm{O}-\mathrm{N}$ and $\mathrm{C}-\mathrm{I} \cdots \mathrm{O}-\mathrm{N}$ interactions through the $\mathrm{N}-\mathrm{O}$ group, giving rise to supramolecular

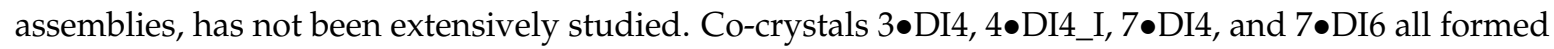
1-D polymers driven majorly by $\mathrm{C}-\mathrm{I} \cdots \mathrm{O}-\mathrm{N}$ interactions; however, $\mathrm{C}-\mathrm{H} \cdots \mathrm{O}$ interactions orthogonal to $\mathrm{XB}$ chains were interpreted as an essential element of the co-crystal structure. For example, in $3 \bullet \mathrm{DI} 4$, the $\mathrm{N}-\mathrm{O}$ group bridged donors at I...O distances of $c a .2 .840 \AA\left(\mathrm{R}_{\mathrm{XB}}=0.81\right)$ and $c a .2 .875 \AA\left(\mathrm{R}_{\mathrm{XB}}=0.82\right)$ with I $\cdots \mathrm{O} \cdots \mathrm{I}$ angles of $c a .139 .6^{\circ}$, leading to 1-D polymers. Orthogonal to $\mu-\mathrm{O}, \mathrm{O}$ XB mode, $\mathrm{C}-\mathrm{H} \cdots \mathrm{O}$ interactions operated between $\mathrm{N}-\mathrm{O}$ groups and $\mathrm{C} 2$-/C6-protons in the ab-plane to form 2-D sheets (Figure 3a). The perfluorinated chains and aromatic rings from adjacent 1-D polymers aggregated through $\mathrm{F} \cdots \mathrm{F}$ and $\mathrm{C}-\mathrm{H} \cdots \mathrm{O}$ interactions, and induced segregation of donors and acceptors in the crystal structure. Similar ortho-C $-\mathrm{H} \cdots \mathrm{O}$ interactions between $\mathrm{N}$-oxide molecules, and donor-acceptor segregated crystal packing motifs were observed in 4•DI4_I, 7•DI4 and 7•DI6 (Figure 3b-d).

(a)

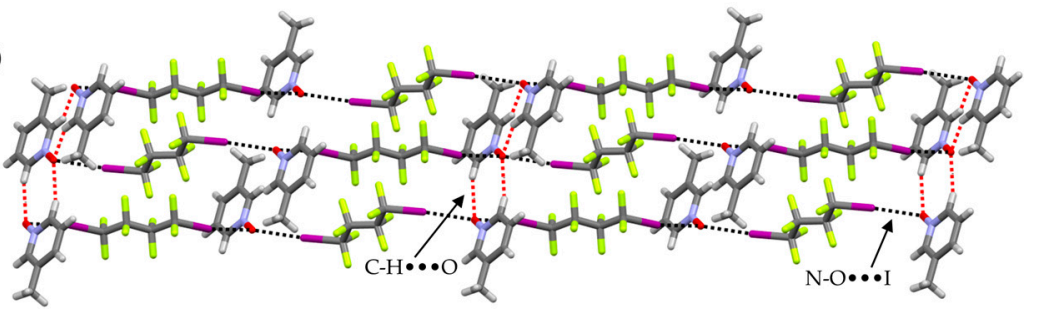

(b)
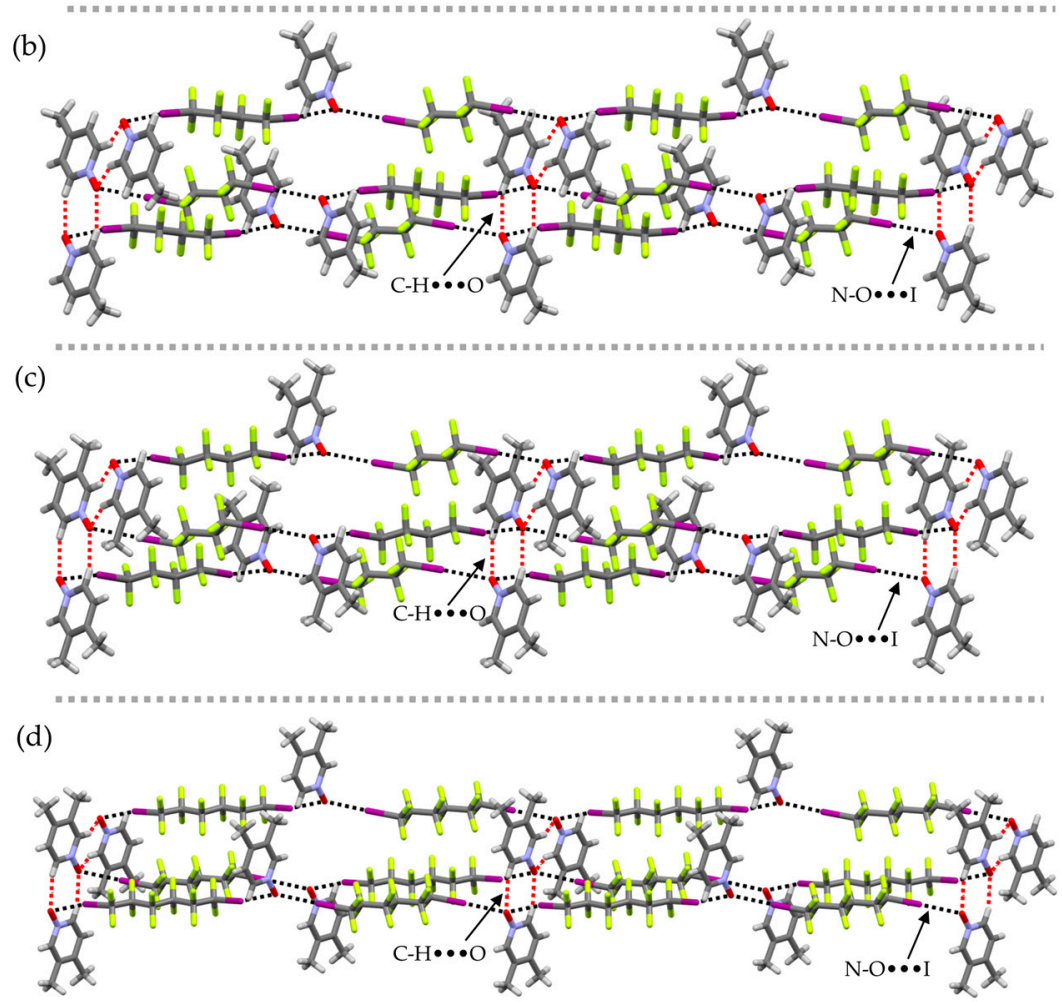

Figure 3. 1-D Halogen bond polymers stitched by adjacent ortho-C $-\mathrm{H} \cdots \mathrm{O}$ interactions in, 3•DI4 (a), 4•DI4_I (b), 7•DI4 (c) and 7•DI6 (d) shown in capped stick models. Black and red broken lines are respectively $\mathrm{XB}$ and $\mathrm{HB}$ interactions. 


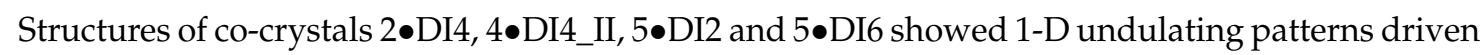
by $\mathrm{C}-\mathrm{I} \cdots \mathrm{O}-\mathrm{N}$ interactions, as depicted in Figure 4 . The $\mathrm{I} \cdots \mathrm{O} \cdots \mathrm{I}$ angles and the centroid-to-centroid distances between aromatic rings occupying the crest and trough sites were directly related. For example, the $2 \bullet$ DI4 $\left(145.2^{\circ}\right)$ and 4•DI4_II $\left(112.2^{\circ}\right)$ manifested a shallow wave appearance, with centroid-to-centroid aromatic distances of $23.2 \AA$ and $19.2 \AA$, respectively. These I ...O...I angles were greater than in 5•DI2 $\left(103.6^{\circ}\right)$ and $5 \bullet$ DI6 $\left(107.8^{\circ}\right)$, which both exhibited sharp interwoven patterns with the respective centroid-to-centroid aromatic distances of $16.9 \AA$ and $17.2 \AA$. In $5 \bullet$ DI2 and 5•DI6, the aromatic rings were orthogonal to $\mu-O, O$ XB mode, favouring closer interdigitation between 1-D chains stabilized by $\mathrm{C}-\mathrm{H} \cdots \mathrm{F}$ interactions. Moreover, the 1-D XB chains were cross-aligned in $2 \bullet$ DI4

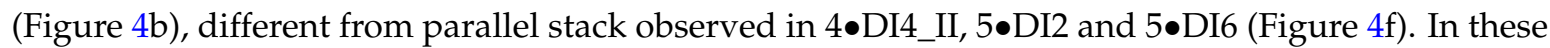
structures, the aromatic rings did not participate in any $\pi \cdots \pi$ interactions, and the structures were sustained by several weak $\mathrm{F} \cdots \mathrm{F}, \mathrm{C}-\mathrm{H} \cdots \mathrm{O}$ and $\mathrm{C}-\mathrm{H} \cdots \mathrm{F}$ interactions.

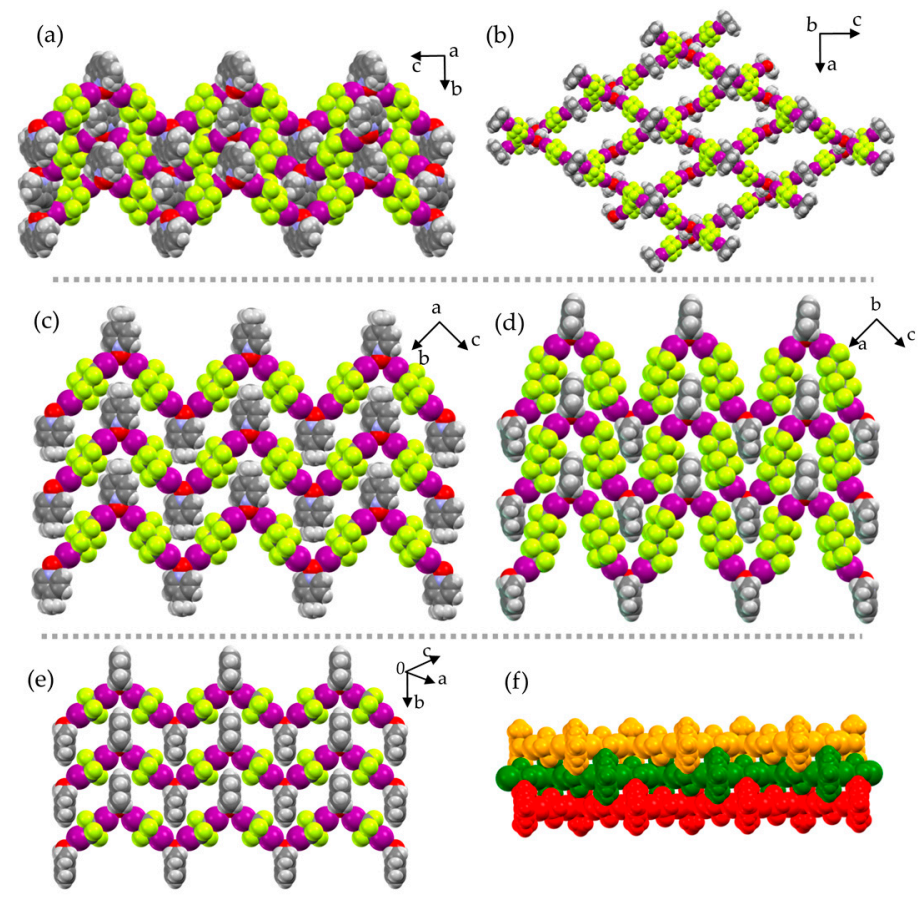

Figure 4. Interwoven by $\mathrm{C}-\mathrm{H} \cdots \mathrm{F}$ interactions, the 1-D undulated XB polymeric chains in $2 \bullet$ DI4 (a),

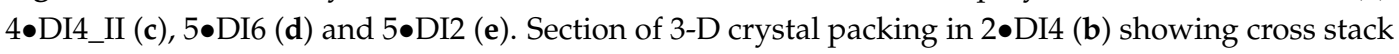

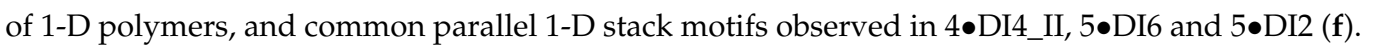

The $\mathrm{N}-\mathrm{O}$ groups in co-crystals $7 \bullet \mathrm{DI} 2$ and $7 \bullet \mathrm{DI} 8$ act as monodentate $\mathrm{XB}$ acceptors with $\mathrm{I} \cdots \mathrm{O}$ distances $c a$. $2.703 \AA\left(\mathrm{R}_{\mathrm{XB}}=0.77\right)$ and $c a .2 .715 \AA\left(\mathrm{R}_{\mathrm{XB}}=0.78\right)$. Contrary to above examples, the $\mathrm{C}-\mathrm{H} \cdots \mathrm{O}$ interactions became more pronounced in $7 \bullet \mathrm{DI} 2$ and $7 \bullet \mathrm{DI} 8$, breaking the XB continuity in 1-D chains, and inducing alternate $\mathrm{XB}$ and cyclic $\mathrm{C}-\mathrm{H} \cdots \mathrm{O}$ interactions as seen in Figure 5. The molecules of 7 could be seen as forming fully planar dimers, which were further connected by XB respectively with DI2 or DI8. In 7•DI2, the offset stacking of the acceptor dimers prevented the formation of F $\cdots \mathrm{F}$ interactions by DI2 (Figure $5 \mathrm{c}$ ). In $7 \bullet$ DI8, due to longer DI8 chains, the $\pi \cdots \pi$ stacking prevented only a half of the perfluorooctane chain from establishing F...F interactions (Figure $5 \mathrm{~d}$ ), with the packing in co-crystals $7 \bullet$ DI2 and $7 \bullet$ DI8 being otherwise quite similar. 

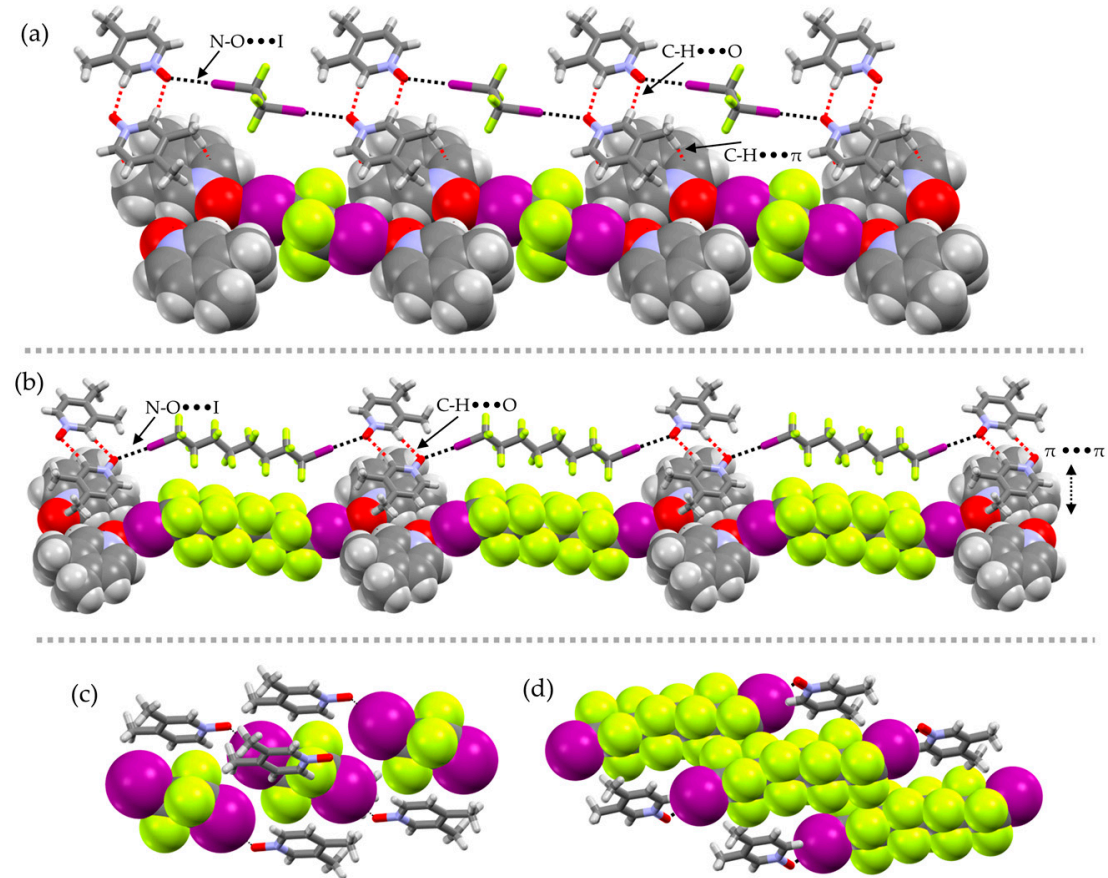

Figure 5. 1-D Chains propagated by alternating $\mathrm{XB}$ and $\mathrm{C}-\mathrm{H} \cdots \mathrm{O}$ interactions in $7 \bullet \mathrm{DI} 2(\mathbf{a})$ and $7 \bullet \mathrm{DI} 8$ (b). Section of crystal packing displaying isolated DI2 in 7•DI2 (c), and partially F $\cdots$ F stabilized DI8 in 7•DI8 (d). Black and red broken lines are respectively XB and HB interactions.

The $6 \bullet$ DI2 exhibited a 1:2 donor-acceptor stoichiometry, crystallizing in the monoclinic space group $P 2_{1} / n$, with the donor molecule DI2 lying on an inversion centre. A XB with $\mathrm{I} \cdots \mathrm{O}$ distances of ca. $2.714\left(\mathrm{R}_{\mathrm{XB}}=0.78\right)$ and two $\mathrm{C}-\mathrm{H} \cdots \mathrm{O}-\mathrm{N}$ interactions at $\mathrm{N}-\mathrm{O}$ group suggested $s p^{3}$ hybridization of the oxygen. The $\mathrm{C}-\mathrm{H} \cdots \mathrm{O}$ interactions played a significant role in the crystal packing. Analysis of the interlayer packing revealed the formation of a 1-D zig-zag HB tape along the b-axis (Figure 6a) through $\mathrm{C}-\mathrm{H} \cdots \mathrm{O}$ interactions between the $\mathrm{N}-\mathrm{O}$ group and the $\mathrm{C} 2$-methyl and $\mathrm{C} 6$-hydrogens. The 1-D tapes were connected by DI2 (Figure 6b) to give 2-D sheets which further stacked along the third dimension, with centroid-to-centroid aromatic distances of $c a .3 .84 \AA$.
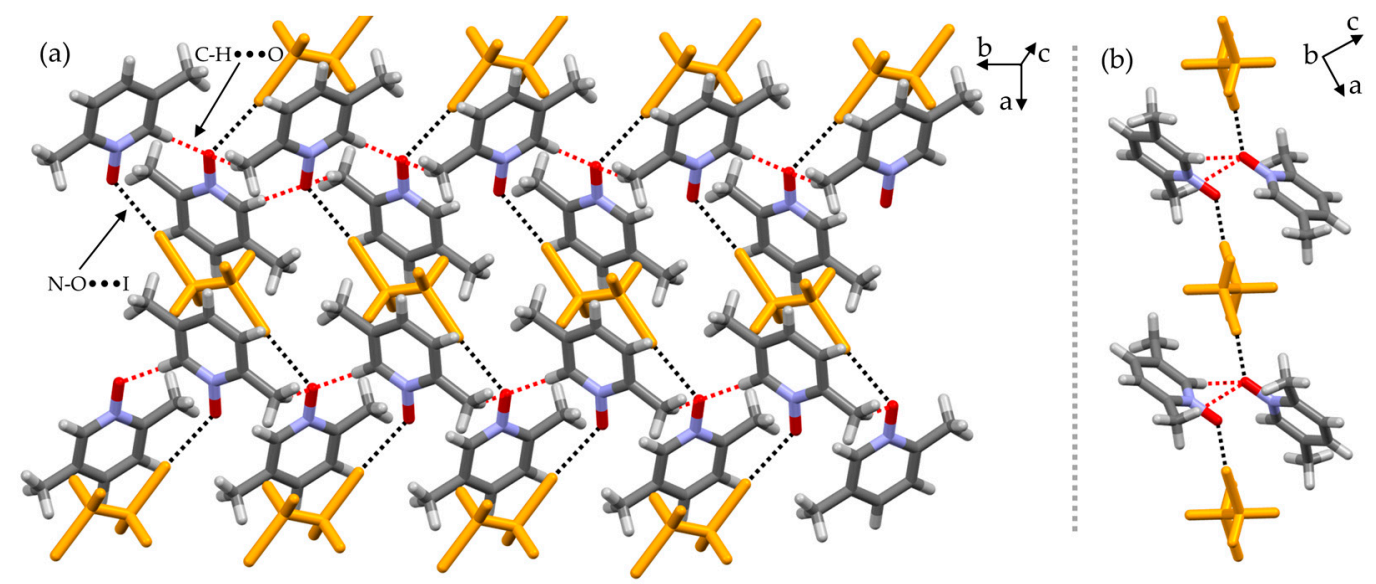

Figure 6. The 1-D Hydrogen bond tapes bridged by DI2 donors (a), and a view along the b-axis showing connecting modes of DI2 (b). Color representation: Gold capped sticks are DI2 donors, black and red broken lines are respectively $\mathrm{XB}$ and $\mathrm{HB}$ interactions. 
Co-crystals $5 \bullet$ DI4, $8 \bullet$ DI2 and 8•DI6 also formed 2:1 acceptor-donor discrete structures (Figure $7 \mathrm{a}-\mathrm{c}$ ), with monodentate $\mathrm{XB}$ acceptor modes for $\mathrm{N}-\mathrm{O}$ groups. In 5•DI4, the 1:2 discrete units propagated along the $b$-axis by $\mathrm{C}-\mathrm{H} \cdots \mathrm{O}$ interactions between $\mathrm{N}-\mathrm{O}$ and methyl groups. Further, the 1-D motifs (Figure 7d) extended three dimensionally through $\mathrm{C}-\mathrm{H} \cdots \mathrm{F}$ and $\pi \cdots \pi$ interactions. Co-crystal $8 \bullet$ DI2 had an interesting 1-D ladder structure (Figure $7 \mathrm{f}$ ), with $\mathrm{N}$-oxides forming 1-D tapes through $\mathrm{C}-\mathrm{H} \cdots \mathrm{O}$ interactions as the side rails (Figure $7 \mathrm{~g}$ ) connected by halogen bonds via DI2. These 1-D ladders further packed through stacking of the aromatic rings as depicted schematically in Figure $7 \mathrm{~h}$. On the other hand, $8 \bullet$ DI6 with its 3:1 acceptor-donor generated a more complex structure, extended by $\pi \cdots \pi$ interactions between $2: 1$ discrete units and the additional, "passive" molecule of $\mathrm{N}$-oxide 8, not involved in XB, as depicted in Figure 7e. While the "passive" molecule of 8, situated near an inversion centre, was disordered over two components with 50:50 occupancies, the anti-gauche conformation of DI6 was not compatible with the presence of an inversion centre in the middle of the C3-C4 bond of the donor.

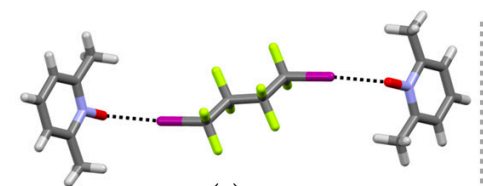

(a)

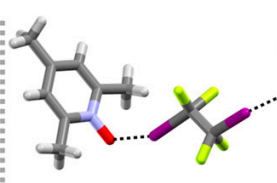

(b)

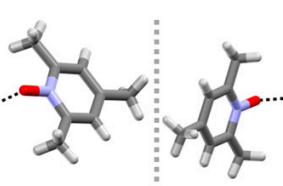

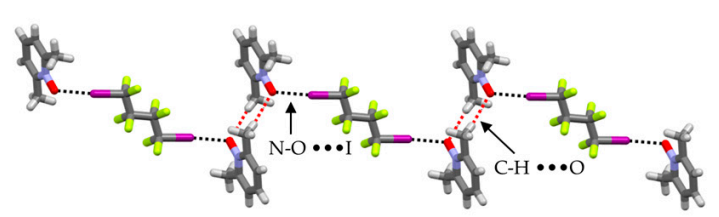

(d)

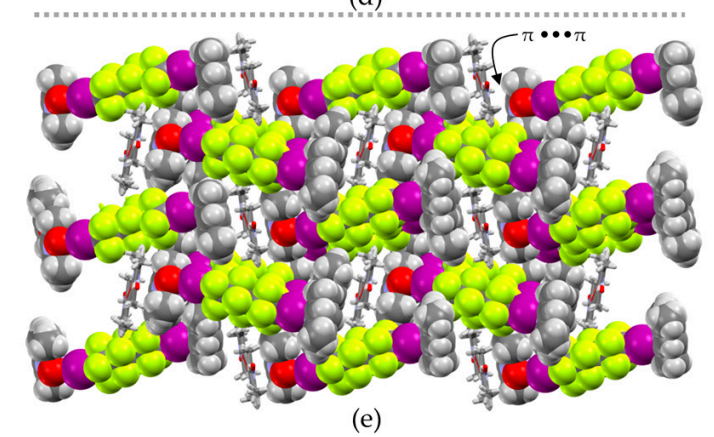

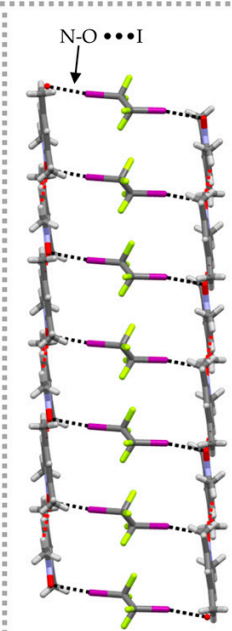

(f)

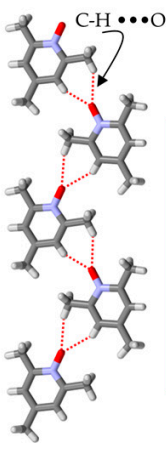

$(\mathrm{g})$

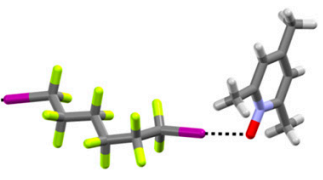

(c)

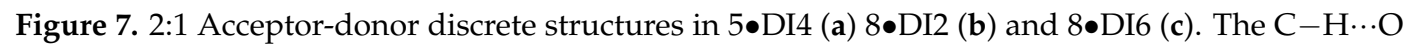
interactions connect the 2:1 units in 5•DI4 (d). Complex crystal packing in 8•DI6 displaying $\pi \cdots \pi$ interactions stabilized 2:1 units (e); 1-D Ladder motif in 8•DI2 (f), and the 1-D HB tapes formed by 8

(g). Cartoon of 1-D ladders illustrating the $\pi-\pi$ stacking in $8 \bullet D I 2(h)$. Black and red broken lines are respectively $\mathrm{XB}$ and $\mathrm{HB}$ interactions.

\section{Conclusions}

Halogen bonding between pyridine $N$-oxides and $1, \omega$-diiodoperfluoroalkanes was found to be a reliable tool for crystal engineering, as witnessed by the successful structural characterization of 17 co-crystals reported here. The $\mathrm{N}$-oxide functionality was able to act as either a monodentate $(6 / 17$ co-crystals) or $\mu-O, O$ bidentate $(11 / 17$ co-crystals) halogen bond acceptor. Monodentate $\mathrm{C}-\mathrm{I} \cdots \mathrm{O}^{-}-\mathrm{N}^{+}$halogen bonds were stronger than bidentate $\mathrm{C}-\mathrm{I} \cdots \mathrm{O}^{-}-\mathrm{N}^{+}$halogen bonds. Based on the observed $\mathrm{R}_{\mathrm{XB}}$ values, ranging from 0.76 to $0.83, \mathrm{C}-\mathrm{I} \cdots \mathrm{O}^{-}-\mathrm{N}^{+}$halogen bonds can be classified as moderately strong compared to e.g. very strong monodentate $\mathrm{N}^{-}-\mathrm{I}^{+} \ldots \mathrm{O}^{-}-\mathrm{N}^{+}$type halogen bonds, previously studied by $u$, which display $\mathrm{R}_{\mathrm{XB}}$ values as low as 0.66 . In addition to that, an important role of weak interactions, such as weak $\mathrm{C}-\mathrm{H} \cdots \mathrm{O}$ hydrogen bonds and aromatic ring stacking, has 
been established. In particular, the $\mathrm{N}$-oxide oxygen atom was shown to simultaneously engage in both the hydrogen and halogen bonding as a mixed acceptor. However, the $\mathrm{C}-\mathrm{H} \cdots \mathrm{O}$ hydrogen bonds were fairly weak, as witnessed by the observation of two polymorphs of $4 \bullet$ DI4, where only one of the two exhibited $\mathrm{C}-\mathrm{H} \cdots \mathrm{O}$ hydrogen bonds. The ability of $\mathrm{N}$-oxide oxygen to act as a $\mu_{2}$ - (one $\mathrm{XB}$ and one $\mathrm{HB}$ ), $\mu_{3}-$ (one $\mathrm{XB}$ and two $\mathrm{HB}$ ) and $\mu_{4}$-acceptor (two XB and two $\mathrm{HB}$ ) is a complex process. For example, the pronounced $\mathrm{C}-\mathrm{H} \cdots \mathrm{O}$ hydrogen bonds between $\mathrm{N}$-oxide oxygen and $\mathrm{C} 2$ - acidic protons can be a result of F ...F interaction [38-42] between adjacent perfluorinated donor chains, resulting in a stable crystal lattice.

\section{Materials and Instrumentation}

All solvents used for crystal growth were of reagent grade, and used as received. Pyridine $\mathrm{N}$-oxide (1), 2-methylpyridine $\mathrm{N}$-oxide (2), 3-methylpyridine $\mathrm{N}$-oxide (3), 4-methylpyridine $\mathrm{N}$-oxide (4), 2,6-dimethylpyridine $\mathrm{N}$-oxide (5) and hexadecafluoro-1,8-diiodooctane (DI8) were purchased from Sigma-Aldrich, while tetrafluoro-1,2-ethane (DI2), octafluoro-1,4-diiodobutane (DI4), and dodecafluoro-1,6-diiodohexane (DI6) were purchased from Apollo Scientific Chemicals Ltd. 2,5-Dimethylpyridine $N$-oxide (6), 3,4-dimethylpyridine $N$-oxide (7) and 2,4,6-trimethylpyridine $\mathrm{N}$-oxide (8) were synthesized as previously reported [29].

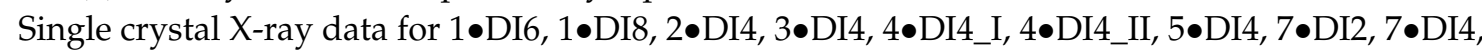
$7 \bullet$ DI6 and 8•DI2 were measured on a Bruker-Nonius Kappa CCD diffractometer (Bruker AXS Inc, Wisconsin, USA) with an APEX-II CCD detector using graphite-monochromated Mo-K $\alpha(\lambda=0.71073$ $\AA$ ) radiation. The data for $3 \bullet \mathrm{DI} 8,5 \bullet \mathrm{DI} 2,5 \bullet \mathrm{DI} 6,6 \bullet \mathrm{DI} 2,7 \bullet \mathrm{DI} 8$, and $8 \bullet$ DI6 were measured on an RigakuOxford single-source diffractometer (Rigaku Corporation, Tokyo, Japan) equipped with an Eos CCD detector using mirror-monochromated Mo- $K \alpha(\lambda=0.71073 \AA)$ radiation. The crystal data and experimental details for the data collections are given in Tables S2-S5. Data collection and reduction for Rigaku Oxford diffractometer were performed using the program CrysAlisPro [55], while for Bruker-Nonius Kappa CCD diffractometer using the program COLLECT [56] and HKL DENZO AND SCALEPACK [57]. A Gaussian face indexing-based absorption correction method [55] was used for

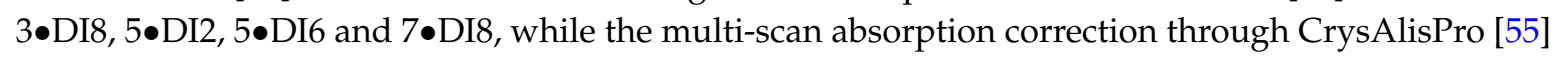

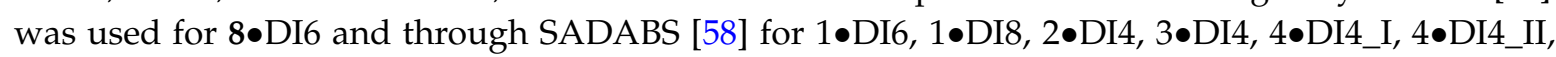

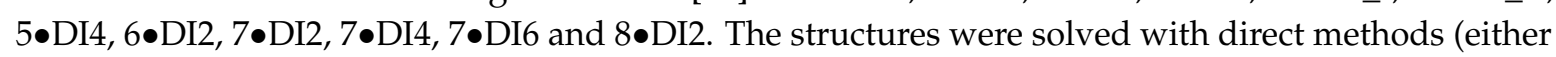
SHELXS or SHELXT) [59] and refined by full-matrix least squares on $F^{2}$ using OLEX2 [60] and/or WinGX [61] which utilize the SHELXL-2016/6 module [59]. No attempt was made to locate the hydrogens from difference electron density Fourier maps, and appropriate constraints and restraints were used when necessary for disordered molecules.

Supplementary Materials: The following are available online at www.mdpi.com/2073-4352/7/7/214/s1, Table S1: Summary of crystallization experiments, Table S2: Crystal data and X-ray experimental details for $1 \bullet D I 4-3 \bullet D I 8$, Table S3: Crystal data and X-ray experimental details for 4•DI4_I-5•DI6. Table S4: Crystal data and X-ray experimental details for $6 \bullet$ DI2-7•DI8. Table S5: Crystal data and X-ray experimental details for $8 \bullet D I 2$ and $8 \bullet$ DI6.

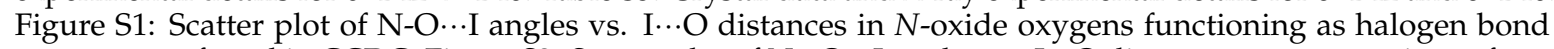
acceptors, as found in CCDC. Figure S2: Scatter plot of N-O - I I angles vs. I .. O distances as a comparison of our previous and current results of $N$-oxide oxygens functioning as halogen bond acceptors.

Acknowledgments: The authors kindly acknowledge the Academy of Finland (Project numbers RP: 298817, KR: 263256, 265328 and 292746) and the University of Jyväskylä for financial support.

Author Contributions: The synthesis of aromatic $N$-oxides and the project design presented in this work were performed by R.P. X-ray analysis and structural solution for eight structures was obtained by R.P., eight by F.T. and one by A.V. The manuscript was written by R.P. and assisted by F.T., and K.R. supervised the work.

Conflicts of Interest: The authors declare no conflict of interest. 


\section{References and Notes}

1. Desiraju, R.G.; Ho, S.P.; Kloo, L.; Legon, C.A.; Marquardt, R.; Metrangolo, P.; Politzer, P.; Resnati, G.; Rissanen, K. Definition of the halogen bond (IUPAC Recommendations 2013). Pure Appl. Chem. 2013, 85, 1711-1713. [CrossRef]

2. Halogen Bonding, 2008th ed.; Metrangolo, P.; Resnati, G. (Eds.) Springer: Berlin, Germany, 2008; Volume 126.

3. Politzer, P.; Murray, J.S. Halogen bonding: An interim discussion. ChemPhysChem 2013, 14, $278-294$. [CrossRef] [PubMed]

4. Politzer, P.; Murray, J.S.; Clark, T. Halogen bonding and other [sigma]-hole interactions: A perspective. Phys. Chem. Chem. Phys. 2013, 15, 11178-11189. [CrossRef] [PubMed]

5. Rissanen, K. Halogen bonded supramolecular complexes and networks. CrystEngComm 2008, 10, 1107-1113. [CrossRef]

6. Troff, R.W.; Mäkelä, T.; Topić, F.; Valkonen, A.; Raatikainen, K.; Rissanen, K. Alternative motifs for halogen bonding. Eur. J. Org. Chem. 2013, 2013, 1617-1637. [CrossRef]

7. Metrangolo, P.; Meyer, F.; Pilati, T.; Resnati, G.; Terraneo, G. Halogen bonding in supramolecular chemistry. Angew. Chem. Int. Ed. 2008, 47, 6114-6127. [CrossRef] [PubMed]

8. Priimagi, A.; Cavallo, G.; Metrangolo, P.; Resnati, G. The halogen bond in the design of functional supramolecular materials: Recent advances. Acc. Chem. Res. 2013, 46, 2686-2695. [CrossRef] [PubMed]

9. Voth, A.R.; Khuu, P.; Oishi, K.; Ho, P.S. Halogen bonds as orthogonal molecular interactions to hydrogen bonds. Nat. Chem. 2009, 1, 74-79. [CrossRef] [PubMed]

10. Bedin, M.; Karim, A.; Reitti, M.; Carlsson, A.-C.C.; Topić, F.; Cetina, M.; Pan, F.; Havel, V.; Al-Ameri, F.; Sindelar, V.; et al. Counterion influence on the $[\mathrm{N}-\mathrm{I}-\mathrm{N}]^{+}$halogen bond. Chem. Sci. 2015, 6, 3746-3756. [CrossRef]

11. Carlsson, A.-C.C.; Gräfenstein, J.; Budnjo, A.; Laurila, J.L.; Bergquist, J.; Karim, A.; Kleinmaier, R.; Brath, U.; Erdélyi, M. Symmetric halogen bonding is preferred in solution. J. Am. Chem. Soc. 2012, 134, 5706-5715. [CrossRef] [PubMed]

12. Carlsson, A.-C.C.; Veiga, A.; Erdélyi, M. Halogen bonding in solution. In Halogen Bonding II SE-607; Metrangolo, P., Resnati, G., Eds.; Springer: Berlin, Germany, 2015; Volume 359, pp. 49-76.

13. Rissanen, K.; Haukka, M. Halonium Ions as Halogen Bond Donors in the Solid State $\left[\mathrm{XL}_{2}\right] Y$ Complexes. In Halogen Bonding II SE-587; Metrangolo, P., Resnati, G., Eds.; Springer: Berlin, Germany, 2015; Volume 359, pp. 77-90.

14. Barluenga, J.; González, J.M.; Campos, P.J.; Asensio, G. I(Py ${ }_{2} \mathrm{BF}_{4}$, a new reagent in organic synthesis: General method for the 1,2-Iodofunctionalization of olefins. Angew. Chem. Int. Ed. 1985, 24, 319-320. [CrossRef]

15. Turunen, L.; Warzok, U.; Puttreddy, R.; Beyeh, N.K.; Schalley, C.A.; Rissanen, K. [N … I ...N] halogen-bonded dimeric capsules from tetrakis(3-pyridyl)ethylene cavitands. Angew. Chem. Int. Ed. 2016, 55, 14033-14036. [CrossRef] [PubMed]

16. Fourmigué, M. Halogen bonding: Recent advances. Curr. Opin. Solid State Mater. Sci. 2009, 13, 36-45. [CrossRef]

17. Nguyen, H.L.; Horton, P.N.; Hursthouse, M.B.; Legon, A.C.; Bruce, D.W. Halogen bonding: A new interaction for liquid crystal formation. J. Am. Chem. Soc. 2004, 126, 16-17. [CrossRef] [PubMed]

18. Metrangolo, P.; Prasang, C.; Resnati, G.; Liantonio, R.; Whitwood, A.C.; Bruce, D.W. Fluorinated liquid crystals formed by halogen bonding. Chem. Commun. 2006, 3290-3292. [CrossRef] [PubMed]

19. Bull, J.A.; Mousseau, J.J.; Pelletier, G.; Charette, A.B. Synthesis of pyridine and dihydropyridine derivatives by regio- and stereoselective addition to $\mathrm{N}$-activated pyridines. Chem. Rev. 2012, 112, 2642-2713. [CrossRef] [PubMed]

20. Xiao, B.; Liu, Z.-J.; Liu, L.; Fu, Y. Palladium-catalyzed C-H activation/cross-coupling of pyridine $N$-oxides with nonactivated secondary alkyl bromides. J. Am. Chem. Soc. 2013, 135, 616-619. [CrossRef] [PubMed]

21. Wu, J.; Cui, X.; Chen, L.; Jiang, G.; Wu, Y. Palladium-catalyzed alkenylation of quinoline- $N$-oxides via C-H activation under external-oxidant-free conditions. J. Am. Chem. Soc. 2009, 131, 13888-13889. [CrossRef] [PubMed]

22. Campeau, L.-C.; Schipper, D.J.; Fagnou, K. Site-selective $s p^{2}$ and benzylic $s p^{3}$ palladium-catalyzed direct arylation. J. Am. Chem. Soc. 2008, 130, 3266-3267. [CrossRef] [PubMed] 
23. Campeau, L.-C.; Bertrand-Laperle, M.; Leclerc, J.-P.; Villemure, E.; Gorelsky, S.; Fagnou, K. C2, C5, and C4 azole $\mathrm{N}$-oxide direct arylation including room-temperature reactions. J. Am. Chem. Soc. 2008, 130, 3276-3277. [CrossRef] [PubMed]

24. Pool, J.A.; Scott, B.L.; Kiplinger, J.L. A new mode of reactivity for pyridine $N$-oxide: C-H activation with uranium(IV) and thorium(IV) bis(alkyl) complexes. J. Am. Chem. Soc. 2005, 127, 1338-1339. [CrossRef] [PubMed]

25. Campeau, L.-C.; Rousseaux, S.; Fagnou, K. A solution to the 2-Pyridyl organometallic cross-coupling problem: Regioselective catalytic direct arylation of pyridine N-oxides. J. Am. Chem. Soc. 2005, 127, 18020-18021. [CrossRef] [PubMed]

26. Adriaenssens, L.; Ballester, P. Hydrogen bonded supramolecular capsules with functionalized interiors: The controlled orientation of included guests. Chem. Soc. Rev. 2013, 42, 3261-3277. [CrossRef] [PubMed]

27. Raynal, M.; Ballester, P.; Vidal-Ferran, A.; van Leeuwen, P.W. Supramolecular catalysis. Part 1: Non-covalent interactions as a tool for building and modifying homogeneous catalysts. Chem. Soc. Rev. 2014, 43, 1660-1733. [CrossRef] [PubMed]

28. Albini, A. Heterocyclic N-oxides; CRC Press: Boca Raton, FL, USA, 1991.

29. Katritzky, A.R.; Lagowski, J.M. Chemistry of the Heterocyclic N-oxides; Academic Press: Cambridge, MA, USA, 1971.

30. Puttreddy, R.; Steel, P.J. 4-Methoxypyridine N-oxide: An electron-rich ligand that can simultaneously bridge three silver atoms. Inorg. Chem. Commun. 2014, 41, 33-36. [CrossRef]

31. Puttreddy, R.; Steel, P.J. Pyridine N-oxide: A hyperdentate argentophile. CrystEngComm 2014, 16, 556-560. [CrossRef]

32. Pang, X.; Jin, W.J. Exploring the halogen bond specific solvent effects in halogenated solvent systems by ESR probe. New J. Chem. 2015, 39, 5477-5483. [CrossRef]

33. Aakeröy, C.B.; Wijethunga, T.K.; Desper, J. Constructing molecular polygons using halogen bonding and bifurcated N-oxides. CrystEngComm 2014, 16, 28-31. [CrossRef]

34. Messina, M.T.; Metrangolo, P.; Panzeri, W.; Pilati, T.; Resnati, G. Intermolecular recognition between hydrocarbon oxygen-donors and perfluorocarbon iodine-acceptors: The shortest $\mathrm{O} \cdots$ I non-covalent bond. Tetrahedron 2001, 57, 8543-8550. [CrossRef]

35. Puttreddy, R.; Jurček, O.; Bhowmik, S.; Makela, T.; Rissanen, K. Very strong ${ }^{-} \mathrm{N}-\mathrm{X}^{+} \ldots{ }^{-} \mathrm{O}^{-\mathrm{N}^{+}}$halogen bonds. Chem. Commun. 2016, 11, 2338-2341. [CrossRef] [PubMed]

36. Ho, P.S. Halogen Bonding I. Top. Curr. Chem. 2015, 358, 241-276. [PubMed]

37. Aakeröy, C.B.; Wijethunga, T.K.; Benton, J.; Desper, J. Stabilizing volatile liquid chemicals using co-crystallization. Chem. Commun. 2015, 51, 2425-2428. [CrossRef] [PubMed]

38. Omorodion, H.; Twamley, B.; Platts, J.A.; Baker, R.J. Further evidence on the importance of fluorous-fluorous interactions in supramolecular chemistry: A combined structural and computational study. Cryst. Growth Des. 2015, 15, 2835-2841. [CrossRef]

39. Baker, R.J.; Colavita, P.E.; Murphy, D.M.; Platts, J.A.; Wallis, J.D. Fluorine-fluorine interactions in the solid state: An experimental and theoretical study. J. Phys. Chem. A 2012, 116, 1435-1444. [CrossRef] [PubMed]

40. Reichenbacher, K.; Suss, H.I.; Hulliger, J. Fluorine in crystal engineering- "The little atom that could". Chem. Soc. Rev. 2005, 34, 22-30. [CrossRef] [PubMed]

41. O'Hagan, D. Understanding organofluorine chemistry. An introduction to the C-F bond. Chem. Soc. Rev. 2008, 37, 308-319. [CrossRef] [PubMed]

42. Berger, R.; Resnati, G.; Metrangolo, P.; Weber, E.; Hulliger, J. Organic fluorine compounds: A great opportunity for enhanced materials properties. Chem. Soc. Rev. 2011, 40, 3496-3508. [CrossRef] [PubMed]

43. Taylor, $\mathrm{R}$. It Isn't, It Is: The $\mathrm{C}-\mathrm{H} \cdots \mathrm{X}(\mathrm{X}=\mathrm{O}, \mathrm{N}, \mathrm{F}, \mathrm{Cl})$ interaction really is significant in crystal packing. Cryst. Growth Des. 2016, 16, 4165-4168. [CrossRef]

44. Dragelj, J.L.; Stanković, I.M.; Božinovski, D.M.; Meyer, T.; Veljković, D.Ž.; Medaković, V.B.; Knapp, E.-W.; Zarić, S.D. C-H/O interactions of aromatic CH donors within proteins: A crystallographic study. Cryst. Growth Des. 2016, 16, 1948-1957. [CrossRef]

45. Ji, W.; Liu, G.; Li, Z.; Feng, C. Influence of $\mathrm{C}-\mathrm{H} \cdots \mathrm{O}$ hydrogen bonds on macroscopic properties of supramolecular assembly. ACS Appl. Mater. Interfaces 2016, 8, 5188-5195. [CrossRef] [PubMed]

46. Jones, C.R.; Baruah, P.K.; Thompson, A.L.; Scheiner, S.; Smith, M.D. Can a C-H‥O interaction be a determinant of conformation? J. Am. Chem. Soc. 2012, 134, 12064-12071. [CrossRef] [PubMed] 
47. Gu, Y.; Kar, T.; Scheiner, S. Fundamental properties of the C-H...O interaction: Is it a true hydrogen bond? J. Am. Chem. Soc. 1999, 121, 9411-9422. [CrossRef]

48. Jiang, L.; Lai, L. C-H...O hydrogen bonds at protein-protein interfaces. J. Biol. Chem. 2002, 277, 37732-37740. [CrossRef] [PubMed]

49. Scheiner, S. Dissection of the factors affecting formation of a C-H ‥O-H-bond. A Case Study. Crystals 2015, 5, 327-345. [CrossRef]

50. Desiraju, G.R.; Vittal, J.J.; Ramanan, A. Crystal Engineering: A Textbook; World Scientific: Singapore, 2011.

51. Babu, N.J.; Reddy, L.S.; Nangia, A. AmideN-oxide heterosynthon and amide dimer homosynthon in cocrystals of carboxamide drugs and pyridine N-oxides. Mol. Pharm. 2007, 4, 417-434. [CrossRef] [PubMed]

52. Goud, N.R.; Babu, N.J.; Nangia, A. Sulfonamide-pyridinen-N-oxide cocrystals. Cryst. Growth Des. 2011, 11, 1930-1939. [CrossRef]

53. Reddy, L.S.; Babu, N.J.; Nangia, A. Carboxamide-pyridine N-oxide heterosynthon for crystal engineering and pharmaceutical cocrystals. Chem. Commun. 2006, 1369-1371. [CrossRef] [PubMed]

54. Puttreddy, R.; Cottam, J.R.A.; Steel, P.J. Anion dependent silver(I) complexes of pyrazine mono- $N$-oxide. RSC Adv. 2014, 4, 22449-22454. [CrossRef]

55. Rigaku Oxford Diffr. 2016; Version 1.171.38.41.

56. Bruker AXS BV. Madison, WI, USA, 1997-2004.

57. Otwinowski, Z.; Minor, W. Processing of X-ray diffraction data collected in oscillation mode. Methods Enzymol. 1997, 276, 307-326. [PubMed]

58. Blessing, R.H. Outlier treatment in data merging. J. Appl. Crystallogr. 1997, 30, 421-426. [CrossRef]

59. Sheldrick, G.M. Crystal structure refinement with SHELXL. Acta Crystallogr. Sect. C 2015, 71, 3-8. [CrossRef] [PubMed]

60. Dolomanov, O.V.; Bourhis, L.J.; Gildea, R.J.; Howard, J.A.K.; Puschmann, H. OLEX2: A complete structure solution, refinement and analysis program. J. Appl. Crystallogr. 2009, 42, 339-341. [CrossRef]

61. Farrugia, L.J. WinGX and ORTEP for Windows: An update. J. Appl. Crystallogr. 2012, 45, 849-854. [CrossRef]

(C) 2017 by the authors. Licensee MDPI, Basel, Switzerland. This article is an open access article distributed under the terms and conditions of the Creative Commons Attribution (CC BY) license (http:/ / creativecommons.org/licenses/by/4.0/). 